Bangladesh J. Bot. 41(2): 169-175, 2012 (December)

\title{
GENETIC DIVERSITY ANALYSIS OF THIRTEEN MUNGBEAN (VIGNA RADIATA (L.) WILCZEK) CULTIVARS USING RAPD MARKERS
}

\author{
Sonia Khan Sony, Md. Ahashan Habib and Mohammad Nurul Islam* \\ Department of Botany, University of Dhaka, Dhaka-1000, Bangladesh
}

Key words: Mungbean, RAPD, Genetic diversity, Cluster analysis

\begin{abstract}
Genetic diversity analysis among 13 mungbean cultivars from Bangladesh was performed through polymerase chain reaction (PCR) based random amplification of polymorphic DNA (RAPD). Out of 20 arbitrary decamer oligonucleotide primers used, 10 produced a total of 379 different bands with an average of 37.9 bands per primer. Based on the observed banding pattern all the primers were found to be $100 \%$ polymorphic. Band size of the amplicons ranged from 250 - $5000 \mathrm{bp}$. A total of 10 unique DNA fragments was amplified from the 13 mungbean cultivars genome. The values of pair-wise genetic distances ranged from 0.0700 - 1.0852, indicating the presence of wide genetic diversity. The highest genetic distance (1.0852) was found between cultivar BARI Mung-2 and 6 while the lowest $(0.0700)$ between cultivar BINA Mung-2 and 7. Dendogram based on Nei's genetic distance using Unweighted Pair Group Method of Arithmetic Means (UPGMA) has segregated the 13 mungbean cultivars into two major clusters. BARI Mung-1, 2, 3, 4 and 5 formed cluster 1 and BARI Mung-6, BINA Mung-1, 2, 7, 6, 4, 5 and 8 have made cluster 2.
\end{abstract}

\section{Introduction}

Mungbean (Vigna radiata (L.)Wilczek) is one of the most important pulse crops in tropics and subtropics. It is an excellent source of easily digestible good quality protein for both humans and domestic animals. The productivity of pulses is very low as compared to cereals, which have been selected for high grain yield under high input conditions (Narasimhan et al. 2010). The major constraints in achieving high yield of this crop are lack of genetic variability, poor harvesting index and susceptibility to diseases and pests. Despite the efforts, development of sustainable resistant cultivar with higher yields has not yet been successful due to narrow genetic bases of the present cultivars. In order to increase the genetic variability, different breeding programs have been undertaken by Bangladesh Agriculture Research Institute (BARI) and Bangladesh Institute of Nuclear Agriculture (BINA). As a consequence 13 advanced mungbean cultivars have been developed (source: BARI and BINA web site). These cultivars were identified on the basis of morphological traits, disease resistance properties and yield attributes. However, no genetic information is available about these materials. For successful breeding program knowledge of genetic diversity is essential and pre-requisite as well. There are numerous techniques available for assessing the genetic variability and relationship among crop germplasms. DNA based molecular markers such as RFLPs, SSRs and RAPDs are effective and reliable tools for measuring genetic diversity and evolutinary relationship among crop germplasms (Kidwell et al. 1994, Mengoni et al. 2000).

Among the DNA markers, development of RAPD-PCR based DNA finger priniting is easier (Gherardi et al. 1998). RAPD markers have been used for the identification and assessing the genetic diversity among cultivars of several crops like mungbean (Saini et al. 2010), Vigna angularis (Yee et al. 1999), Medicago sativa L. (Mohammadzadeh et al. 2011), Oryza sativa L. (Easmin et al. 2008) and Black gram (Srivastava et al. 2011). Moreover, the genetic knowledge helps to compare each germplasm and to choose competent parents for hybridization.

*Author for correspondence: <mnurul@du.ac.bd>. 
Therefore, the objective of the present study was to investigate and compare the RAPD finger printing based genetic diversity among 13 mungbean cultivars released from BARI and BINA.

\section{Materials and Methods}

The seeds of 13 mungbean cultivars viz. BARI Mung-1, 2, 3, 4, 5, 6, BINA Mung-1, 2, 4, 5, 6, 7 and 8 were collected from BARI and BINA, respectively (Table 2). The plant materials were maintained in the Botanic garden, Department of Botany, University of Dhaka. DNAs used in RAPD-PCR experiment were isolated from the leaf tissues of the plants.

Total genomic DNA was extracted by using modified CTAB method (Doyle and Doyle 1987). DNA concentration was quantified through spectrophotometer (Analylikjena, Specord 50, Germany). The A260/280 readings for DNA samples were 1.6 - 1.8.

The PCR reaction mixture for $25 \mu \mathrm{l}$ containing template DNA (25 ng) $2 \mu \mathrm{l}$, de-ionized distilled water $18.8 \mu \mathrm{l}$ and Taq buffer A $10 \times(10 \mathrm{mM}$ Tris-HCl with $1.5 \mathrm{mM} \mathrm{MgCl}$ ) $2.5 \mu \mathrm{l}$, primer $(10 \mu \mathrm{M}) 1.0 \mu \mathrm{l}$, dNTP mix $(10 \mathrm{mM}) 0.5 \mu \mathrm{l}$, Taq DNA polymerase $(5 \mathrm{U} / \mu \mathrm{l}) 0.2 \mu \mathrm{l}$. PCR amplification was done in an oil-free thermal cycler (Biometra UNOII, Germany) for 46 cycles after initial denaturation $94^{\circ} \mathrm{C}$ for $5 \mathrm{~m}$, denaturation at $94^{\circ} \mathrm{C}$ for $1 \mathrm{~m}$, annealing at $36^{\circ} \mathrm{C}$ for $30 \mathrm{~s}$, extension at $72^{\circ} \mathrm{C}$ for $3 \mathrm{~m}$ and final extension at $72^{\circ} \mathrm{C}$ for $5 \mathrm{~m}$. Initially 20 random primers were used in the present study for screening but OPA-1 (CAG GCC CTT C), OPA-2 (TGC CGA GCT C), OPA-3 (AGT CAG CCA C), OPA-4 (AAT CGG GCT G), OPA-5 (AGG GGT CTT G), OPA6 (GGT CCC TGA C), OPA-7 (GAA ACG GGT G), OPA-8 (GTG ACG TAG G), OPA-9 (GGG TAA CGC C), OPA-10 (GTC ATC GCA G) showed reproducible results (Table 1).

The amplified products were separated electrophoretically on $1 \%$ agarose gel. The gel was prepared using 1.0 gm agarose powder containing ethidium bromide $(0.5 \mu \mathrm{g} / \mathrm{ml})$ and $100 \mathrm{ml} 1 \times$ TAE buffer. Agarose gel electrophoresis was conducted in $1 \times$ TAE buffer at $50 \mathrm{~V}$ and $100 \mathrm{~mA}$ for 1.5 hrs. A $1.0 \mathrm{~kb}$ DNA ladder was electrophoresed alongside the RAPD reactions as marker. DNA bands were observed on UV-trans-illuminator and photographed by a gel documentation system (CSL-Microdoc Sytem, Cleaver Scientific Ltd., USA).

The PCR products were analyzed after gel electrophoresis. The photographs were critically discussed on the basis of presence (1) or absence (0) of bands, size of bands and overall polymorphism of bands. The scores obtained using all primers in the RAPD analysis were then pooled for constructing a single data matrix. This was used for estimating polymorphic loci, Nei's (1972) gene diversity, genetic distance (D) and constructing a UPGMA (Unweighted Pair Group Method of Arithmetic Means) dendrogram among the cultivars using computer program "POPGENE" (Version 1.31) (Yeh et al. 1999).

\section{Results and Discussion}

A total of 20 decamer random primers was used in 13 mungbean cultivars for RAPD analysis. However, only ten primers have been found to be reproducible in same PCR banding profile and produced 379 bands (Fig. 1). Size of the amplified polymorphic bands ranged from 250 - 5000 bp. Among the ten primers, OPA-4 produced maximum of 72 bands whereas minimum 18 bands were observed in primer OPA-9 (Table 1). Moreover, 10 unique bands were identified in different primer combinations. The average bands per primer were 37.9. Lakhanpaul et al. (2000) and Saini et al. (2004) reported 12.71 and 9.3 bands per primer, respectively. Afzal et al. (2004) also obtained low number of bands (6.0) per primer in this species. The present primer combinations thus gave much more avarage bands than the earlier reports of this species. These bands can be used as cultivar specific markers in order to make patent for each cultivar (Table 1). 
The values of pair-wise Nei's (1972) genetic distance ranged from 0.0700 - 1.0852 (Table 2). The highest genetic distance (1.0852) was found between cultivar BARI Mung-2 and 6 and the lowest between BINA Mung-2 and 7. The difference between the highest and the lowest value of genetic distance revealed the wide range of variability persisting among the 13 mungbean cultivars. Wide range of genetic diversity $(0-0.48)$ was also reported in 54 mungbean accessions (Lavanya et al. 2008). Undal et al. (2011) observed limited genetic diversity (0.42 - 0.57) among seven species of Vigna.

Table 1. RAPD finger printing with ten primers in thirteen mungbean cultivars.

\begin{tabular}{lccccc}
\hline $\begin{array}{c}\text { Primer } \\
\text { codes }\end{array}$ & Sequences & $\begin{array}{c}\text { Total } \\
\text { bands } \\
\text { obtained }\end{array}$ & $\begin{array}{c}\text { Band size } \\
\text { range (bp) }\end{array}$ & $\begin{array}{c}\text { No. of unique } \\
\text { bands (bp) }\end{array}$ & $\begin{array}{c}\text { No. of } \\
\text { polymorphic } \\
\text { bands }\end{array}$ \\
\hline OPA-1 & CAGGCC CTT C & 54 & $2500-450$ & 0 & 54 \\
OPA-2 & TGC CGA GCT C & 52 & $3000-300$ & 0 & 52 \\
OPA-3 & AGT CAG CCA C & 23 & $2250-300$ & $\begin{array}{c}\text { BINA Mung-8:1 (300) } \\
\text { BARI Mung-6:3 (900, 1700, 2000) }\end{array}$ \\
& & & & & 23 \\
OPA-4 & AAT CGG GCT G & 72 & $5000-300$ & BARI Mung-4:2 (2000, 5000) & 72 \\
OPA-5 & AGG GGT CTT G & 42 & $1500-250$ & 0 & 42 \\
OPA-6 & GGT CCC TGA C & 28 & $1400-300$ & 0 & 28 \\
OPA-7 & GAA ACG GGT G & 29 & $1400-300$ & 0 & 29 \\
OPA-8 & GTG ACG TAG G & 42 & $2000-250$ & BARI Mung-4:1(900) & 42 \\
OPA-9 & GGG TAA CGC C & 18 & $1500-500$ & BINA Mung-4:1(1000) & 18 \\
OPA-10 & GTC ATC GCA G & 19 & $1000-250$ & BINA Mung-1:1(250) & 19 \\
& & & \multicolumn{4}{c}{ BARI Mung-6:1(1000) } \\
\end{tabular}

The dendogram constructed based on Nei's (1972) genetic distance segregated the 13 mungbean cultivars into two major clusters (Fig. 2). BARI Mung-1, 2, 3, 4, 5 formed cluster 1 and BARI Mung-6, BINA Mung-1, 2, 7, 6, 4, 5 and 8 have made cluster 2. In cluster 1, BARI Mung-1, 2 and 3 formed sub-cluster 1(SC1). BARI Mung-4 and 5 made group 1 in this cluster. Again in SC1, BARI Mung-3 alone formed group 2 while BARI Mung-1 and 2 formed group 3.

In cluster 2, BARI Mung-6 alone formed separate group 4. BINA Mung-1, 2, 7, 6, 4, 5 and 8 comprised sub-cluster 2 (SC2). In SC2, BINA Mung- 5 formed group 5 and BINA Mung-8 made group 6. On the other hand, BINA Mung-1, 2, 7, 6 and 4 formed sub sub-cluster 1 (SSC1). In SSC1, BINA Mung-1 formed group 7 and BINA Mung-2, 7, 6 and 4 formed cluster SSC1.1. Again in cluster SSC1.1, BINA Mung-2, 7, 6 and 4 subsequently formed group 8, 9 and 10, respectively. BINA Mung-2 was closer to the 7 with least genetic distance. In cluster 1, BARI Mung-1, 2, 3, 4 and 5 formed subcluster-1, so that they are maintaining closest genetic relationship. In cluster 2, BARI Mung-6 alone formed individual group and was distinctly separate from the other cultivars of sub-cluster 2 (Fig. 2).

The foregoing discussion clearly indicate that each of the 13 mungbean cultivars possessed specific RAPD finger printing profile which would be helpful to patent them by BARI and BINA. Moreover, BINA Mung-2 and 7 could be used as potential parents in plant breeding program for the development of mungbean cultivar. 


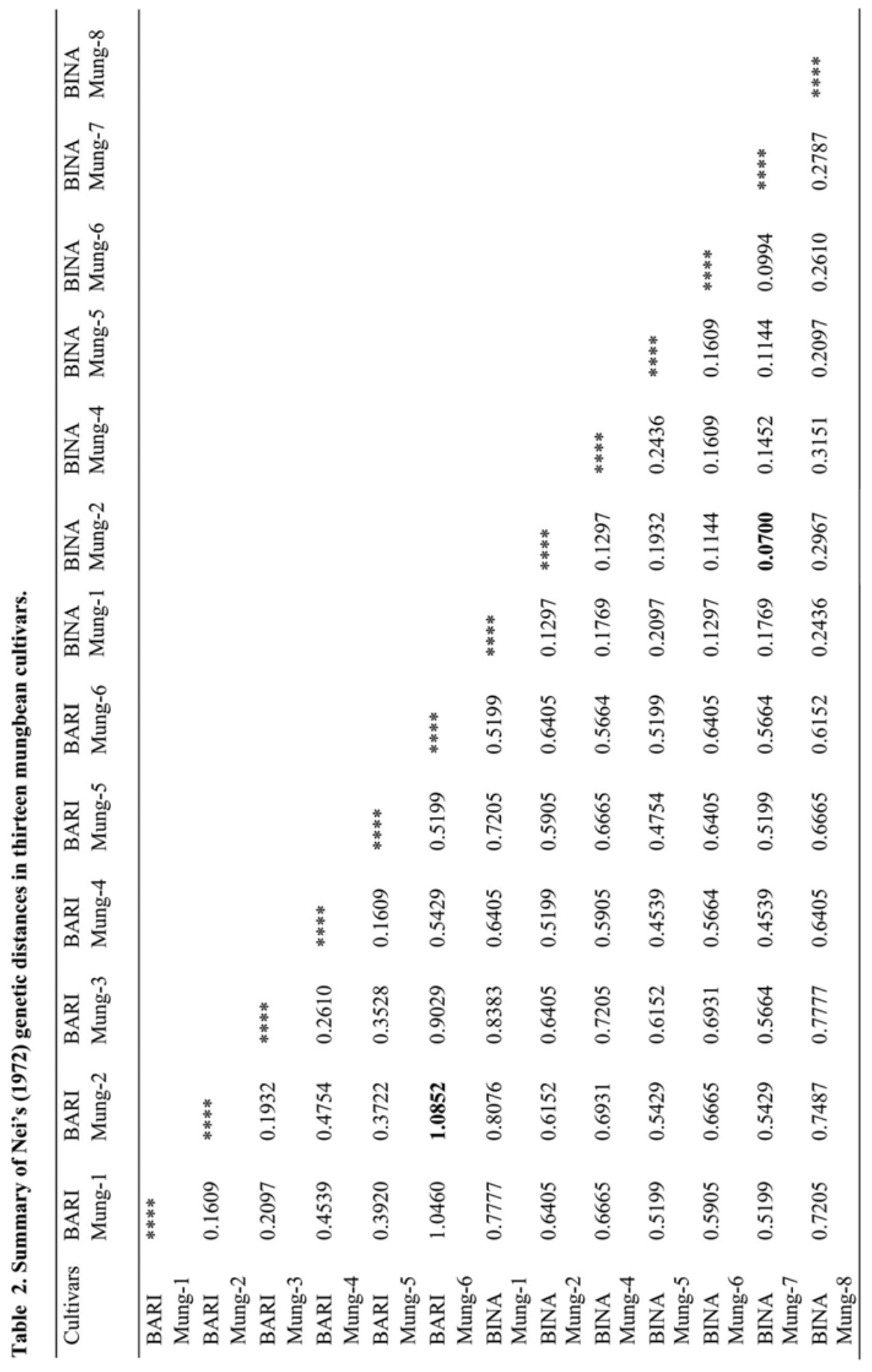



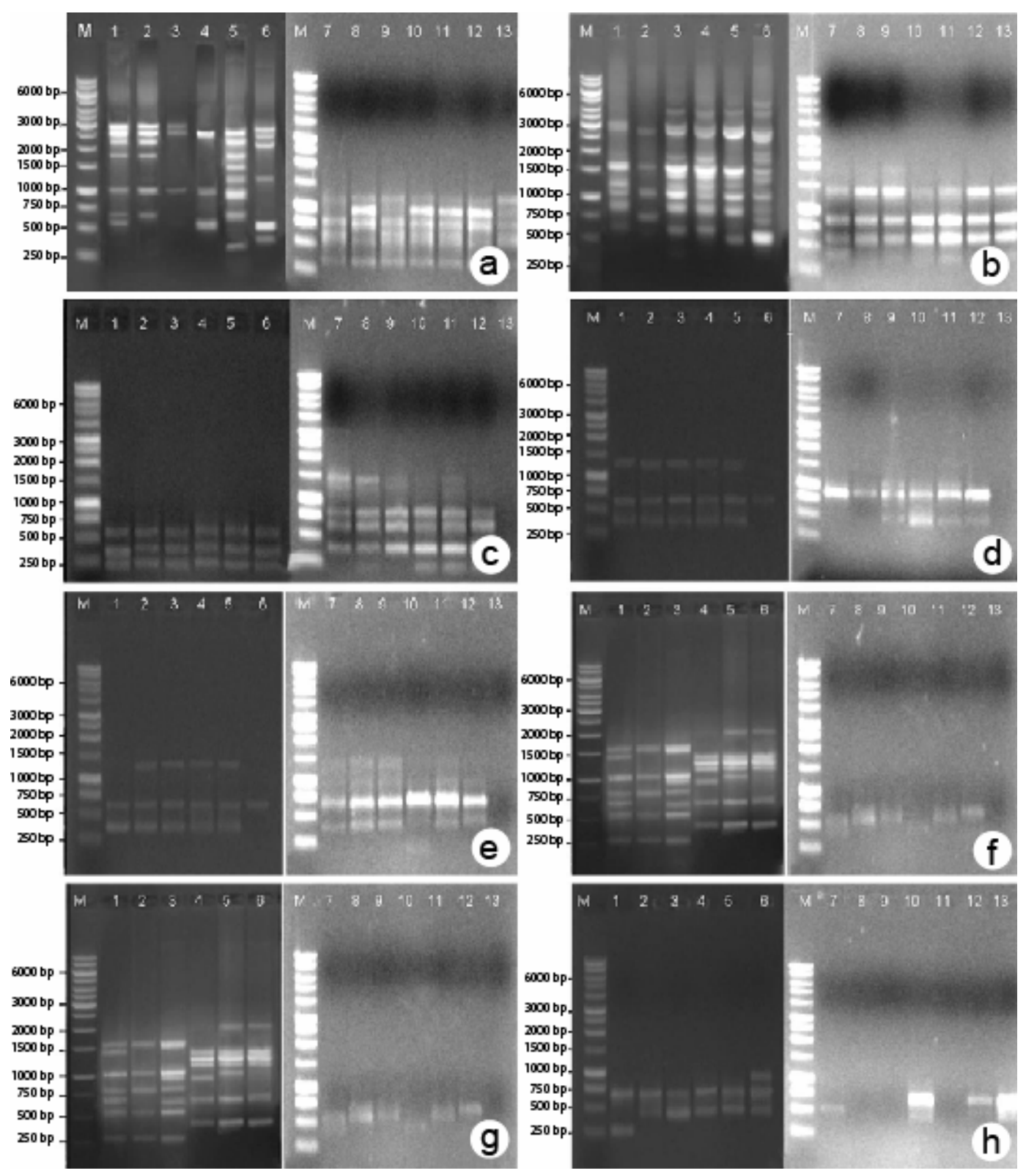

Fig. 1. RAPD profile obtained from 13 mungbean cultivars DNA with (a) primer OPA-2, (b) primer OPA-4, (c) primer OPA-5, (d) primer OPA-6, (e) primer OPA-7, (f) primer OPA-8, (g) primer OPA-9 and (h) primer OPA-10. Lane M - 1.0 Kb marker, lane 1 - BARI Mung-1, lane 2 - BARI Mung-2, lane 3 BARI Mung-3, lane 4 - BARI Mung-4, lane 5 - BARI Mung-5, lane 6 - BARI Mung-6, lane 7 - BINA Mung-1, lane 8 - BINA Mung-2, lane 9 - BINA Mung-4, lane 10 - BINA Mung-5, lane 11 - BINA Mung-6, lane 12 - BINA Mung-7 and lane 13 - BINA Mung-8. 


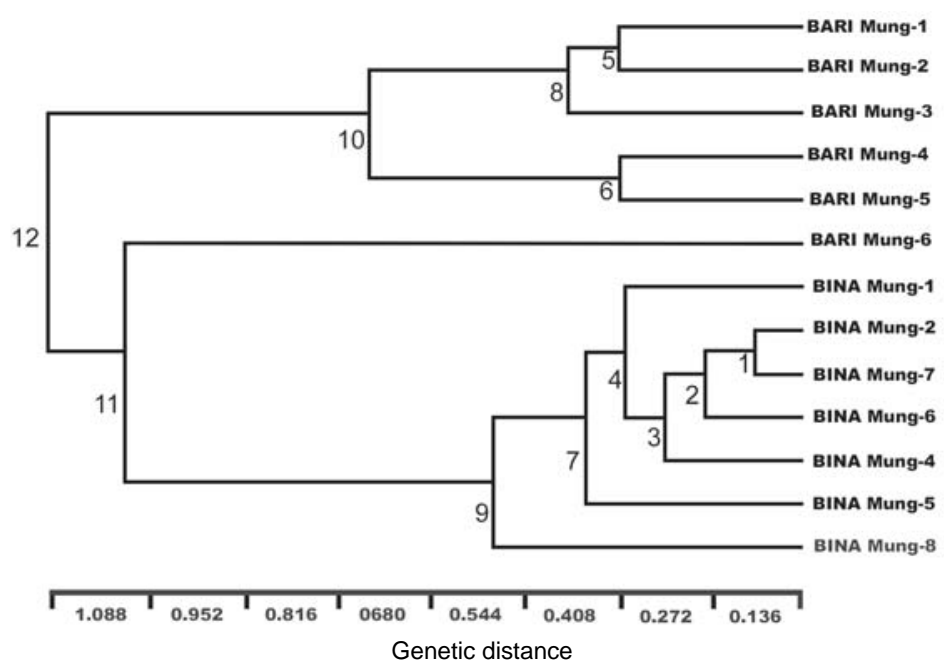

Fig. 2. UPGMA dendogram baased on RAPD analysis of 13 mungbean cultivars as per Nei’s (1972).

\section{References}

Afzal MA, Haque MM and Shanmugasundaram S 2004. Random amplified polymorphic DNA (RAPD) analysis of selected mungbean (Vigna radiata L. Wilczek) cultivars. Asian J. Pl. Sci. 3: 20-24.

Doyle JJ and Doyle JL 1987. A rapid DNA isolation procedure from small quantities of fresh leaf tissues. Phytochem. Bull. 19: 11-15.

Easmin F, Rahman MS, Islam MS, Samad MA and Alam MS 2008. Genetic variation and relatedness among high yielding rice cultivars (Oryza sativa L.) revealed by RAPD markers. Bangladesh J. Pl. Breed. and Genet. 21(1): 07-14.

Gherardi M, Mangin B, Goffinet B, Bonnet D and Huguet T 1998. A method to measure genetic distance between allogamous populations of alfalfa (Medicago sativa) using RAPD molecular markers. Theor. Appl. Genet. 96: 406-412.

Kidwell KK, Austinand DF and Osborn TC 1994. RFLP evaluation of nine Medicago accessions representing the original germplasm sources of North American alfalfa cultivars. Crop Sci. 34: 230-236.

Lakhanpaul S, Chanda S and Bhat KV 2000. Random amplified polymorphic DNA (RAPD) analysis in Indian mungbean (Vigna radiata (L.) Wilczek) cultivers. Genetica 109: 227-234.

Lavanya GR, Srivastava J and Ranade SA 2008. Molecular assessment of genetic diversity in mungbean germplasm. J Genet. 87: 65-74.

Mengoni A, Goriand A and Bazzicalupo M 2000. Use of RAPD and microsatellite (SSR) variation to assess genetic relationships among populations of tetraploid alfalfa, Medicago sativa. Pl. Breed. 119: 311-317.

Mohammadzadeh F, Monirifar H, Saba J, Valizadeh M, Haghighi AR, Zanjani BM, Barghi M and Tarhriz V 2011. Genetic variation among Iranian Alfalfa (Medicago sativa L.) populations based on RAPD markers. Bangladesh J. Plant. Taxon. 18 (2): 93-104.

Narasimhan A, Patil BR, Datta S and Kaashyap M 2010. Genetic diversity assessment across different genotypes of mungbean and urdbean using molecular markers. Electro. J. Plant Breed. 1(4): 379-383.

Nei M 1972. Genetic distance between populations. Amer. Nat. 106: 283-292.

Saini A, Reddy KS and Jawali N 2004. Evaluation of long primers for AP-PCR analysis of mungbean (Vigna radiata (L.) Wilczek): Genetic relationships and fingerprinting of some genotypes. Indian J. Biotech. 3: 511-518. 
Saini M, Singh S, Hussain Z and Yadav A 2010. RAPD analysis in mungbean (Vigna radiata (L.) Wilczek): I. Assessment of genetic diversity. Indian J. Biotech. 9:137-140.

Srivastava P, Pandey A and Sinha DP 2011. Genetic diversity analysis in different cultivars of black gram using RAPD markers. J. Pl. Breed. Crop Sci. 3(3): 53-59.

Undal VS, Thakare PV, Chaudhari US, Deskukhand VP and Gawande PA 2011. Estimation of genetic diversity among wild Vigna species revealed by RAPD markers. Ann. Biol. Res. 2: 348-354.

Yee E, Kidwell KK, Sills GR and Lumpkin TA 1999. Diversity among selected Vigna angularis (Azuki) accessions on the basis of RAPD and AFLP markers. Crop Sci. 29: 268-275.

Yeh FC, Yang RC and Boyle T 1999. POPGENE Version 1.31: Microsoft Window-based Free software for Population Genetic Analysis. http://www.ualberta.ca/ fy.ch/

http://www.bari.gov.bd/achievements (retrive date 04.05.2012)

http://www.bina.gov.bd/achievements (retrive date 04.05.2012)

(Manuscript received on 2 May, 2012; revised on 10 November, 2012) 